\title{
The Aging Incarcerated Population: Evaluating Two Decades of Upward Trends
}

\section{Current Research in Psychology and Behavioral Science (CRPBS)}

\author{
Volume 2, Issue 2, 2021
}

Article Information

Received date : 09 November, 2021

Published date: 30 November, 2021

\section{*Corresponding author}

Vasiliki Georgoulas-Sherry, Teachers College, Columbia University, 525 West 120th St. New York, NY 10027, USA

Key Words

Corrections; Aging; Gerontology; Incarcerated Individuals; Health Care

Distributed under: Creative Commons CC-BY 4.0

\author{
Vasiliki Georgoulas-Sherry ${ }^{1 *}$ and Hanna G Hernandez ${ }^{2}$ \\ ${ }^{1}$ Teachers College, Columbia University, USA \\ ${ }^{2}$ California State University, USA
}

\section{Abstract}

The aging prison population encompasses the fastest rising age category in the US prison system and are continuing to receive national focus due to its high economic and social costs. Due to their confinement status, the aging incarcerated individuals are subject to insufficient health care and risky lifestyles and behaviors. This leads to an even more rapid progression of these concerns than commonly found in typical aging populations. Due to this, correctional departments are challenged to provide the necessary care and support. This study reviewed snapshots of 1998, 2008, and 2018 incarcerated population data from a mid-sized correctional department in efforts to evaluate the trends of the aging incarcerated population (ages 55 or older) over the past two decades. The findings highlight:

a) The prevalence of the aging incarcerated population and the change in populations over the past two decades;

b) The similarities and differences between the aging and non-aging incarcerated populations;

c) The factors that distinguish the 1998, 2008, and 2018 aging incarcerated population; and

d) The recidivism and violation rates of the 1998, 2008, and 2018 incarcerated population.

This endeavor helped gain insight and knowledge into the impact of the aging incarcerated population. Studies like this one benefit in providing consideration to policy changes focusing on the geriatric population, attention to the aging population's physical and mental health, and evaluation of new programs that can positively impact the aging incarcerated population.

The Aging Incarcerated Population: Evaluating Two Decades of Upward Trends

The incarcerated population is growing older, as individuals 55 years or older continue to be the fastest increasing age category. Correctional departments are challenged to provide the necessary care and support due to the aging prison population's high economic and social costs [1-4]. In part, this has been attributed to the physical, mental, and social health and care needs associated with the overall aging population. Incarcerated individuals also present characteristics 10 to 15 years above their actual chronological age $[3,4]$. Due to incarceration, the aging individuals are exposed to inadequate health care and harming lifestyles, which leads to more rapid progression of chronic illnesses, and cognitive and physical disabilities, than usually found in aging non-incarcerated populations [2]. The rates of incarcerated individuals have decreased nationwide, reflecting the new laws and policies that have yielded a reduction in the growth of correctional involvement $[3,5,6]$. This change has helped with sustaining costs and expenses in both courts and corrections, as well as decreased crime rates [6]. However, notwithstanding the overall decreasing rates of incarcerated individuals, one age group has increased in population-the aging [5] (Cloyes \& Burns 2015). According to Carson and Sabol (2016) [5], since 1993, the number of aging incarcerated individuals (defined in this study as 55 and older) increased by $266 \%$ in state and federal prisons, from 3\% in 1993 to $11 \%$ in 2013. Most recently, research has reported that the aging incarcerated individuals (defined in this study as 50 and older) make up about $16 \%$ of the federal and state prison population suggesting a continued growth [3]. Predictive analyses have shown that by 2030, a third of all incarcerated individuals will be 55 or older.

According to Nowotny et al. [6], the growing rate of the aging incarcerated population stems from stricter laws requiring mandatory minimum and lengthier sentences, parole and probation restrictions, and the two- and three-strike laws. There has also been an increase in the admission of individuals who are 55 years or older; particularly, since 1993, there was about four times as many individuals (55 or older) admitted into state correctional facilities [5]. Outside of criminogenic considerations, the increased rate of aging incarcerated individuals originates from the economic, medical, technological, and social advances over illnesses and injuries - individuals are living longer lives. While this increased aging trend signifies a triumph of great medical and technological advances, it also represents substantial challenges. With aging comes physical, mental, and social health and care concerns. However, due to confinement status, the aging incarcerated individuals are exposed to even more challenges and risks. According to Linder [2], the aging incarcerated individuals are subject to limitations on diet, exercise, preventative and primary care, unhealthy behaviors, and more exposure to violent and risky behaviors. This consequently leads to even more health difficulties than commonly found in typical aging populations. Additionally, recent research has shown that aging incarcerated individuals are likely to exhibit more individual and social developmental needs than non-incarcerated aging individuals, which results to even more exposure to risk factors and acceleration in aging [2,4]. Along with these challenges of increased rates of aging incarcerated individuals, comes the increased economic toll. These physical, mental, social and health complications produce unique hardships and can impose needs for more staff, more training, and more structural accessibility adaptations [2,4,7]. In 2013, Ahalt et al. [7] revealed that the annual cost of prison increased to over $\$ 77$ billion, due to the increased rates of aging incarcerated individuals as they are more susceptible to prolonged health conditions. Research from the American Civil Liberties Union (ACLU) (2012) revealed that correctional departments and taxpayers pay as much as double $(\$ 70,000$ compared to $\$ 34,000)$ to house an incarcerated individual who was 55 years or older versus incarcerated individuals who were 54 years or younger. Additional findings showed that aging incarcerated individuals were twice as costly as their younger counterpart. 
While the rates of aging incarcerated individuals are increasing and the rates of nonaging individuals are decreasing, the rates of recidivism are inverse. Current research has shown the recidivism rate for the aging population is significantly lower than any other age category [4]. Particularly, rates of recidivism decreased significantly with age, regardless of level of education or prior violent crime convictions and sentences [8]. Additionally, rates of re-arrest were also significantly lower in aging individuals than their younger counterpart; after an eight-year follow-up period, the US Sentencing Commission $(2005)[9,10]$ revealed that less than $15 \%$ of aging individuals (defined in this study as 65 or older) were rearrested compared to $68 \%$ of individuals who were 21 years or younger. Due to the significant cost of the aging incarcerated individuals and the small recidivism rates, states have made several attempts to enact policies to reduce the rate of aging incarcerated individuals.

\section{Current Study}

Previous research has shown that the overall aging population poses unique physical, mental, and social health and care needs $[3,6]$. When exposed to confinement, incarcerated individuals are more likely to be subjected to risk factors (e.g., dietary limitations, exposure to violent behavior, stressful conditions) which can accelerate aging [4], and also present characteristics 10 to 15 years above their chronological age. Correctional departments are challenged to provide the necessary care and support due to the aging prison population's high economic and social costs. Further understanding this trend and population is essential in recognizing and identifying the impacts that the aging incarcerated population poses. This study first describes the overall incarcerated population over the past two decades, 1998 to 2018, to evaluate the overall trends of incarceration in terms of age, and then compares the aging versus non-aging incarcerated individuals, and then evaluates the aging incarcerated individuals over the past two decades. Second, this study will compare recidivism rates and violations of the 1998 and 2008 snapshot incarcerated population. The intention of this study can help gain insight and knowledge into how the growing incarcerated population may impact correctional departments.

\section{Methods}

\section{Participants}

Our investigation included a convenience sample from a mid-sized correctional department 1998, 2008, and 2018 December snapshot populations of incarcerated individuals who were either 54 years or younger or 55 years or older; all individuals were at least 18 years or older. In 1998, the snapshot population of incarcerated individuals $(\mathrm{N}=13,978) ; 13,394$ of those incarcerated individuals were 54 years or younger while the rest $(\mathrm{n}=584)$ were 55 years or older. In 2008, the snapshot population of incarcerated individuals $(\mathrm{N}=17,192) ; 15,971$ of those incarcerated individuals were 54 years or younger while the rest $(n=1,221)$ were 55 years or older. In 2018 , the snapshot population of incarcerated individuals $(\mathrm{N}=17,835) ; 15,550$ of those incarcerated individuals were 54 years or younger while the rest $(\mathrm{N}=2,285)$ were 55 years or older (see Table 1$)$. There is the possibility that an individual was present in more than one group due to lengthy sentences or multiple incarcerations. There were 3,312 individuals present in 1998 and 2008 and 4,381 individuals were incarcerated in 2008 and in 2018. There were 1,237 individuals who were incarcerated in 1998,2008, and 2018 .

Table 1: Incarcerated individuals over the past two decades, 1998 to 2018, by age and gender.

\begin{tabular}{|c|c|c|c|c|c|c|}
\hline \multirow{2}{*}{ Age } & \multicolumn{2}{|c|}{1998} & \multicolumn{2}{c|}{ 2008 } & \multicolumn{2}{c|}{2018} \\
\cline { 2 - 7 } & N & $\%$ & N & $\%$ & N & $\%$ \\
\hline Total & 13,978 & $100 \%$ & 17,192 & $100 \%$ & 17,835 & $100 \%$ \\
\hline $18-24$ & 2,840 & 20.3 & 2,527 & 14.7 & 1,562 & 8.8 \\
\hline Males & & 20.6 & & 14.9 & & 8.8 \\
\hline Females & & 17 & & 11.8 & & 8 \\
\hline $25-29$ & 2,571 & 18.4 & 3,114 & 18.1 & 2,835 & 15.9 \\
\hline Males & & 18.4 & & 18.2 & & 15.6 \\
\hline Females & & 18.3 & & 23.5 & & 18.8 \\
\hline $30-34$ & 2,399 & 17.2 & 2,528 & 14.7 & 3,085 & 17.3 \\
\hline
\end{tabular}

\begin{tabular}{|c|c|c|c|c|c|c|}
\hline Males & & 16.9 & & 14.6 & & 17 \\
\hline Females & & 20.3 & & 14.5 & & 20.9 \\
\hline $35-39$ & 2,246 & 16.1 & 2,550 & 14.8 & 2,955 & 16.6 \\
\hline Males & & 15.7 & & 14.6 & & 16.4 \\
\hline Females & & 20.8 & & 16.7 & & 18.6 \\
\hline $40-44$ & 1,706 & 12.2 & 2,191 & 12.7 & 2,027 & 11.4 \\
\hline Males & & 12.2 & & 12.5 & & 11.4 \\
\hline Females & & 12.1 & & 11.4 & & 10.5 \\
\hline $45-49$ & 1,030 & 7.4 & 1,859 & 10.8 & 1,677 & 9.4 \\
\hline Males & & 7.5 & & 10.8 & & 9.5 \\
\hline Females & & 6.3 & & 9.8 & & 8.2 \\
\hline $50-54$ & 602 & 4.3 & 1,202 & 7 & 1,409 & 7.9 \\
\hline Males & & 4.4 & & 7.1 & & 8 \\
\hline Females & & 3 & & 5.3 & & 6.7 \\
\hline $55-59$ & 280 & 2 & 612 & 3.6 & 1,051 & 5.9 \\
\hline Males & & 2.1 & & 3.6 & & 6 \\
\hline Females & & 1.2 & & 3.1 & & 5.1 \\
\hline $60-64$ & 158 & 1.1 & 321 & 1.9 & 615 & 3.4 \\
\hline Males & & 1.2 & & 1.9 & & 3.6 \\
\hline Females & & -- & & 1.8 & & 2 \\
\hline$>=65$ & 146 & 1.1 & 288 & 1.7 & 619 & 3.5 \\
\hline Males & & 1.1 & & 1.8 & & 3.7 \\
\hline Females & & -- & & 2 & & 1.3 \\
\hline$<=54$ & 13,394 & 95.8 & 15,971 & 92.9 & 15,550 & 87.2 \\
\hline$>=55$ & 584 & 4.2 & 1,221 & 7.1 & 2,285 & 12.8 \\
\hline Mean age & 34.1 & & 36.7 & & 39.1 & \\
\hline Median age & 33 & & 35 & & 37 & \\
\hline
\end{tabular}

Note: Snapshots of December 1998, 2008, and 2018 populations were utilized for analyses. Detail may not sum to total due to rounding. Age is described in years.

\section{Materials}

Several measures were utilized to further evaluate and understand the aging population. These measures included various demographic characteristics such as gender, age, homelessness status, and race/ethnicity. Additionally, offense type (i.e., the worst offense at the time of snapshot, violent (i.e., murder, manslaughter, sex offense, and assault) or non-violent (i.e., drug, robbery, and property)), custody level (i.e. supervision level categorized as closed, maximum, medium, or minimum), prior prison, sentence length (i.e., time from admission to release or Expected Release Date (ERD)), time served (i.e., time from admission date to snapshot date), and time to serve (i.e., time from snapshot date to release date or ERD). In order to assess the recidivism (i.e., charges incurred within the first three years following prison release that resulted in a conviction and prison re-admission) rates and violations were also assessed in the analyses. In this report, aging was defined as individuals who were 55 years or older.

\section{Experimental design}

To examine the aging population, a quasi-experimental design was utilized to compare individuals who were either aging or non-aging. A snapshot date of December $31^{\text {st }}$ was used for all three years (i.e., 1998, 2008, and 2018) to assess the incarcerated sample population. 


\section{Results}

The overall number of incarcerated individuals increased $27.6 \%$ over the past two decades, from 13,978 in 1998 to 17,835 in 2018 (see Table 1). This age increase represents a shift in a larger aging population. Only one age group maintained a continued decrease of rates-incarcerated individuals age 24 and younger; all other age groups fluctuated in rates. During 1998 to 2018, the rate of non-aging incarcerated individuals decreased $8.6 \%$ of the overall population, from $95.8 \%$ in 1998 to $87.2 \%$ in 2018 . Aging incarcerated individuals showed the inverse trend, from $4.2 \%$ in 1998 to $12.8 \%$ in 2018 , tripling the rates. The largest rate increase of incarcerated individuals, within 1998 to 2008, was with those who were 55 to 59, at an $80 \%$ increase. In 2008 to 2018, the largest rate increase of incarcerated individuals was with those who were 70 to 74 , at a $175 \%$ increase. In both decades, the aging population showed an increase of $109.1 \%$ and $87.1 \%$, from 1998 to 2008 and 2008 to 2018, respectively. Gender and race/ethnicity discrepancies in the past two decades were reviewed (see Table 1). For gender, rates of males and females age 55 or older increased at a greater pace (207\% and $277.3 \%$, respectively) from 1998 to 2018 . By the end of 2018 , over $8.3 \%$ of the total female incarcerated population were 55 or older and $13.2 \%$ of the overall male incarcerated population were 55 or older, compared to the $2.2 \%$ and $4.3 \%$, respectively, in 1998 . On the contrary, rates of males age 54 or younger decreased at a greater pace (8.2\%) from 2008 to 2018 and rates of females age 54 or younger decreased at a greater pace (4.8\%) from 1998 to 2008 . By the end of 2018, about $92 \%$ of the total female incarcerated population were 54 or younger and $85 \%$ of the overall male incarcerated population were 54 or younger. For race/ethnicity, from 1998 to 2008 , rates of Hispanic incarcerated individuals who were 55 years or older increased $43.5 \%$ and non-hispanic white incarcerated individual rates increased $59.3 \%$ while rates of non-Hispanic black incarcerated individuals who were 55 years or older increased at the greatest pace (165\%). From 2008 to 2018, rates for non-Hispanic black incarcerated individuals who were 55 years or older increased at the greatest pace $(117 \%)$, while rates for non-Hispanic white and Hispanic incarcerated individuals who were 55 years or older increased at $84.9 \%$ and $63.6 \%$, respectively. Over the past 2 decades (1998-2018), rates for non-hispanic black incarcerated individuals 55 or older increased the most at $475 \%$ while non-Hispanic white and Hispanic incarcerated individuals 55 or older increased at much slower rates, $194 \%$ and $135 \%$, respectively.

Unfolding the 1998 incarcerated population by age (54 or younger and 55 or older)

The characteristics of the 1998 incarcerated population by age $(<=54$ or $>=55)$ in terms of custody level, offense type, and prior prison, to name a few, were exhibited on (Table 2). Similar demographic characteristics were found regardless of age. Statistical differences between aging and non-aging individuals were found in prior prison involvement $\left(\mathrm{X}^{2}(1, \mathrm{~N}=13,978)=7.47, \mathrm{p}=.0063\right)$ and homelessness status $\left(\mathrm{X}^{2}\right.$ $(1, \mathrm{~N}=13,978)=8.05, \mathrm{p}=.0046)$ suggesting that the non-aging cohort were more likely to have prior prison involvement and be homeless prior to prison admission. Additionally, age and custody level statistically differed $\left(\mathrm{X}^{2}(3, \mathrm{~N}=13,512)=33.53, \mathrm{p}<.001\right)$ showing that aging incarcerated individuals were more likely to be placed in minimum custody $(70.4 \%)$ and less likely to be placed in maximum custody than their younger counterpart. In terms of offense type, individuals differed in age $\left(\mathrm{X}^{2}(7, \mathrm{~N}=13,977)=337.19, \mathrm{p}<.001\right)$ suggesting that aging individuals were more likely to commit a violent crime $(79 \%)$ than those nonaging $(49.3 \%)$. Lastly, individuals age impacted sentence length $\left(X^{2}(4, N=13,978)=192.04\right.$ $\mathrm{p}<.001)$ as the aging cohort served at least 10 years of their sentence $(32.4 \%)$ and had at least 10 more $(12.3 \%)$, compared to the $4.5 \%$ and $10.2 \%$ of their younger cohort, respectively.

Table 2: Percentage of incarcerated individuals characteristics in Yearend 1998.

\begin{tabular}{|c|c|c|c|c|c|c|c|}
\hline & $<=\mathbf{5 4}$ & $>=\mathbf{5 5}$ & Total & & $<=\mathbf{5 4}$ & $>=\mathbf{5 5}$ & Total \\
\hline Total (N) & 13,394 & 584 & 13,978 & Custody Level & & & \\
\hline Age & & & & Minimum & 59.6 & 70.4 & 60 \\
\hline Mean & 32.9 & 61.4 & 34.1 & Medium & 22.8 & 20 & 22.7 \\
\hline Median & 32 & 60 & 33 & Closed & 12.7 & 6.8 & 12.4 \\
\hline Gender & & & & Maximum & 1.6 & -- & -- \\
\hline Female & 7.3 & 3.8 & 7.2 & $\begin{array}{c}\text { Sentence } \\
\text { Length }\end{array}$ & & & \\
\hline Male & 92.7 & 96.2 & 92.8 & $<2$ years & 39.3 & -- & -- \\
\hline Race & & & & $2-5$ years & 23.7 & 24 & 23.7 \\
\hline
\end{tabular}

\begin{tabular}{|c|c|c|c|c|c|c|c|}
\hline White & 57.1 & 75.2 & 57.9 & $5.1-10$ years & 17 & 23.1 & 17.3 \\
\hline Black & 22.8 & 11 & 22.2 & $>10$ years & 17.6 & 35.4 & 17.3 \\
\hline Hispanic & 13.4 & 7.2 & 13.1 & LWOP & 2.3 & -- & -- \\
\hline Other & 6.6 & 6.7 & 6.6 & Time Served & & & \\
\hline Prior & & & & $<=1$ year & 58.5 & 31.2 & 57.3 \\
\hline Prison & 33.2 & 27.7 & 32.9 & $1-2$ years & 11.7 & 10.4 & 11.7 \\
\hline Homeless & & & & $2.1-3$ years & 8.3 & 7.7 & 8.3 \\
\hline Yes & 9.5 & 6 & 9.3 & $3.1-4$ years & 5.4 & 9.2 & 5.5 \\
\hline Offense & & & & $4.1-6$ years & 6.8 & 12.7 & 7 \\
\hline Murder & 12.1 & 19.3 & 12.4 & $6.1-10$ years & 4.8 & 10.6 & 5.1 \\
\hline Manslaughter & 1.6 & 2.1 & 1.6 & $>=10$ years & 4.5 & 18.2 & 5 \\
\hline Sex Offense & 20.4 & 48.1 & 21.5 & Time to Serve & & & \\
\hline Robbery & 9.8 & 3.6 & 9.5 & $<=1$ year & 53.7 & 39.6 & 53.1 \\
\hline Assault & 15.2 & 9.4 & 15 & $1-2$ years & 10.4 & 12.5 & 10.5 \\
\hline Property & 15.8 & 5.7 & 15.4 & $2.1-3$ years & 7 & 7.2 & 7 \\
\hline Drug & 22.3 & 10.4 & 21.8 & $3.1-4$ years & 5.8 & 9.4 & 6 \\
\hline & & & & $4.1-6$ years & 6.6 & 9.6 & 6.7 \\
\hline & & & & $6.1-10$ years & 6.3 & 9.4 & 6.4 \\
\hline P. & & & & $>=10$ years & 10.2 & 12.3 & 10.3 \\
\hline P. & & & & & & & \\
\hline
\end{tabular}

Note: Due to low Ns, some data were removed. Detail may not sum to total due to rounding. Age is described in years. Offense is defined as the worst crime sentenced. Sentence length is defined as length of stay from admission date to release date (or expected release date). Time served is defined as the length of stay from admission date to December 31, 1998. Time to serve is defined as the length of stay from December 31, 1998 to release date (or expected release date).

Unfolding the 2008 incarcerated population by age (54 or younger and 55 or older)

The characteristics of the 2008 incarcerated population by age $(<=54$ or $>=55)$ in terms of custody level, offense type, and prior prison, to name a few, were presented on (Table 3). Similar to 1998, 2008 cohort showed no significant differences in demographic characteristics. Statistical differences were found for prior prison involvement $\left(\mathrm{X}^{2}\right.$ $(1, \mathrm{~N}=17,192)=60.45, \mathrm{p}<.001)$ and homelessness $\left(\mathrm{X}^{2}(1, \mathrm{~N}=17,192)=16.41, \mathrm{p}<.001\right)$, following 1998's trend. Statistical differences were found in custody level ( $\mathrm{X}^{2}$ (3, $\mathrm{N}=16,248)=53.11, \mathrm{p}<.001)$ suggesting that aging individuals were less likely to be placed in maximum custody (1.1\%) and were more likely to be placed in minimum custody $(73.8 \%)$ than their younger peers. In addition, individuals differed in age and offense type, $\left(\mathrm{X}^{2}(7, \mathrm{~N}=17,192)=714.04, \mathrm{p}<.001\right)$ showing that most aging individual were serving a sentence for violent offenses (77.6\%), compared to non-aging individuals (51.2\%). Lastly significant differences were shown in sentence length and age $\left(X^{2}(4, N=17,191)=550.36\right.$, $\mathrm{p}<.001)$ in that aging individuals served at least 10 years of their sentence $(32.4 \%)$ and had at least ten more years (15.9\%), compared to the $7.7 \%$ and $10.4 \%$ of their younger counterpart, respectively.

Table 3: Percentage of Incarcerated Individuals Characteristics in Yearend 2008

\begin{tabular}{|c|c|c|c|c|c|c|c|}
\hline & $<=54$ & $>=55$ & Total & & $<=54$ & $>=55$ & Total \\
\hline Total (N) & 15,971 & 1,221 & 17,192 & Custody Level & & & \\
\hline Age & & & & Minimum & 62.2 & 73.8 & 63 \\
\hline Mean & 34.8 & 61.2 & 36.7 & Medium & 18.3 & 15.9 & 18.1 \\
\hline Median & 34 & 59 & 35 & Closed & 10.9 & 7 & 10.6 \\
\hline Gender & & & & Maximum & 2.8 & 1.1 & 2.7 \\
\hline
\end{tabular}




\begin{tabular}{|c|c|c|c|c|c|c|c|}
\hline Female & 7.9 & 5 & 7.7 & $\begin{array}{l}\text { Sentence } \\
\text { Length }\end{array}$ & & & \\
\hline Male & 92.1 & 95 & 92.3 & $<2$ years & 42.8 & 21.3 & 40.1 \\
\hline Race & & & & $2-5$ years & 19.2 & 12.3 & 18.3 \\
\hline White & 60.7 & 75.5 & 61.7 & 5.1-10 years & 13 & 13.8 & 13.1 \\
\hline Black & 19 & 13.7 & 18.7 & $>10$ years & 22.7 & 40.4 & 24.9 \\
\hline Hispanic & 11.6 & 5.2 & 11.2 & LWOP & 2.3 & 12.2 & 3.6 \\
\hline Other & 8.7 & 5.6 & 8.4 & Time Served & & & \\
\hline Prior & & & & $<=1$ year & 56.9 & 27.8 & 54.9 \\
\hline Prison & 43 & 31.6 & 42.2 & $1-2$ years & 9.9 & 8.4 & 9.8 \\
\hline Homeless & & & & $2.1-3$ years & 6.6 & 6.3 & 6.6 \\
\hline Yes & 11.3 & 7.7 & 11.2 & 3.1-4 years & 5.1 & 4.9 & 5.1 \\
\hline Offense & & & & $4.1-6$ years & 6.6 & 10.2 & 6.9 \\
\hline Murder & 11.5 & 23.9 & 12.3 & $6.1-10$ years & 7.1 & 10 & 7.3 \\
\hline Manslaughter & 2 & 1.3 & 2 & $>=10$ years & 7.7 & 32.4 & 9.4 \\
\hline Sex & 18.6 & 42.8 & 20.3 & Time to Serve & & & \\
\hline Robbery & 9.6 & 4.8 & 9.3 & $<=1$ year & 57.3 & 43.2 & 56.3 \\
\hline Assault & 19.2 & 9.7 & 18.5 & $1-2$ years & 9.5 & 10.1 & 9.5 \\
\hline Property & 21.2 & 6 & 20.1 & $2.1-3$ years & 6 & 6.8 & 6 \\
\hline \multirow[t]{4}{*}{ Drug } & 13.9 & 9.2 & 13.5 & $3.1-4$ years & 4.4 & 5.1 & 4.4 \\
\hline & & & & 4.1-6 years & 5.9 & 8.4 & 6 \\
\hline & & & & $6.1-10$ years & 6.6 & 10.7 & 6.9 \\
\hline & & & & $>=10$ years & 10.3 & 15.8 & 10.7 \\
\hline
\end{tabular}

Note: Due to low Ns, some data were removed. Detail may not sum to total due to rounding. Age is described in years. Offense is defined as the worst crime sentenced. Sentence length is defined as length of stay from admission date to release date (or expected release date). Time served is defined as the length of stay from admission date to December 31, 2008. Time to serve is defined as the length of stay from December 31, 2008 to release date (or expected release date).

Unfolding the 2018 incarcerated population by age (54 or younger and 55 or older)

The characteristics of the 2018 incarcerated population by age $(<=54$ or $>=55)$ in terms of risk and custody level, offense type, and prior prison, to name a few, were shown on (Table 4). While there were no significant differences in demographic characteristics, there were significant difference regarding prior prison involvement $\left(\mathrm{X}^{2}\right.$ $(1, \mathrm{~N}=17,835)=38.38, \mathrm{p}<.001)$, and homelessness status $\left(\mathrm{X}^{2}(1, \mathrm{~N}=17,835)=18.14, \mathrm{p}<.001\right)$, in that the younger population had higher rates in both categories. Individuals did differ by age and custody level $\left(\mathrm{X}^{2}(3, \mathrm{~N}=16,617)=50.17, \mathrm{p}<.001\right)$ suggesting that, similarly to 1998 and 2008 , that aging individuals were less likely placed in maximum custody $(.8 \%)$ and more likely placed in minimum custody $(70.0 \%)$ than their younger cohort. Additionally, individuals differed by age and offense type, $\left(\mathrm{X}^{2}(7, \mathrm{~N}=17,835)=907.77\right.$, $\mathrm{p}<.001$ ) showing that $79 \%$ of aging individuals ages were serving for violent offenses, then those younger (49.3\%). Lastly, individuals did differ by sentence length and age ( $\mathrm{X}^{2}$ $(4, \mathrm{~N}=17,834)=1070.23, \mathrm{p}<.001)$ in that $36.1 \%$ of aging individuals served at least 10 years and had at least ten more years (14.7\%), compared to the $9.4 \%$ and $11.4 \%$ of non-aging individuals, respectively.

Table 4: Percentage of incarcerated individuals characteristics in year end 2018

\begin{tabular}{|c|c|c|c|c|c|c|c|}
\hline & $<=\mathbf{5 4}$ & $>=\mathbf{5 5}$ & Total & & $<=54$ & $>=\mathbf{5 5}$ & Total \\
\hline Total $(\mathrm{N})$ & 15,550 & 2,285 & 17,835 & Custody Level & & & \\
\hline Age & & & & Minimum & 61.6 & 69.8 & 62.6 \\
\hline
\end{tabular}

\begin{tabular}{|c|c|c|c|c|c|c|c|}
\hline Mean & 35.8 & 61.8 & 39.1 & Medium & 20.6 & 19.5 & 20.5 \\
\hline Median & 35 & 60 & 37 & Closed & 8.6 & 6 & 8.3 \\
\hline Gender & & & & Maximum & 2 & 0.8 & 1.8 \\
\hline Female & 8.5 & 5.3 & 8.1 & Sentence Length & & & \\
\hline Male & 91.5 & 94.7 & 91.9 & $<2$ years & 42.9 & 21.2 & 40.1 \\
\hline Race & & & & 2-5 years & 19.2 & 12.5 & 18.2 \\
\hline White & 56.4 & 72.3 & 58.5 & 5.1-10 years & 12.9 & 13.8 & 13 \\
\hline Black & 18 & 15.9 & 17.7 & $>10$ years & 22.7 & 40.2 & 24.9 \\
\hline Hispanic & 14.7 & 5.6 & 13.6 & LWOP & 2.3 & 12.3 & 3.6 \\
\hline Other & 10.9 & 6.1 & 10.3 & Time Served & & & \\
\hline Prior & & & & $<=1$ year & 55.5 & 29.8 & 52.2 \\
\hline Prison & 48.2 & 41.3 & 47.3 & 1-2 years & 10.1 & 7.3 & 9.8 \\
\hline Homeless & & & & 2.1-3 years & 6.3 & 4.6 & 6.1 \\
\hline Yes & 11.4 & 8.4 & 11 & $3.1-4$ years & 4.4 & 3.7 & 4.3 \\
\hline Offense & & & & 4.1-6 years & 6.2 & 6.3 & 6.2 \\
\hline Murder & 12.2 & 23.8 & 13.7 & $6.1-10$ years & 8.1 & 12.3 & 8.6 \\
\hline Manslaughter & 2.4 & 1.7 & 2.3 & $>=10$ years & 9.4 & 36.1 & 12.8 \\
\hline Sex & 17.2 & 36.8 & 19.7 & Time to Serve & & & \\
\hline Robbery & 9 & 5.4 & 8.6 & $<=1$ year & 57.7 & 50.7 & 56.8 \\
\hline Assault & 24.2 & 13.8 & 22.9 & 1-2 years & 10.1 & 9.2 & 10 \\
\hline Property & 23.3 & 9.5 & 21.6 & 2.1-3 years & 5.8 & 7.3 & 6 \\
\hline \multirow[t]{4}{*}{ Drug } & 8.8 & 6.3 & 8.4 & $3.1-4$ years & 3.8 & 4.3 & 3.9 \\
\hline & & & & 4.1-6 years & 5.2 & 6.5 & 5.4 \\
\hline & & & & $6.1-10$ years & 6.1 & 7.8 & 6.3 \\
\hline & & & & $>=10$ years & 11.3 & 14.2 & 11.6 \\
\hline
\end{tabular}

Note: Due to low Ns, some data were removed. Detail may not sum to total due to rounding. Age is described in years. Offense is defined as the worst crime sentenced. Sentence length is defined as length of stay from admission date to release date (or expected release date). Time served is defined as the length of stay from admission date to December 31, 2018. Time to serve is defined as the length of stay from December 31, 2018, dependent on snapshot population) to release date (or expected release date).

\section{Comparing the 1998, 2008 and 2018 aging incarcerated population}

In evaluating the similarities and differences of the snapshot 1998, 2008 and 2018 aging incarcerated population, it is important to note potential for duplication in records (104 individuals were in the 1998 and 2008 snapshot populations, 317 individuals were in the 2008 and 2018 snapshot populations, and 29 individuals were in all three snapshot populations). From 1998 to 2018, the distribution of gender and race/ethnicity. The proportion of aging males and females continued to increase throughout the decades, $\left(\mathrm{X}^{2}(6, \mathrm{~N}=4,090)=4095.18, \mathrm{p}<.001\right)$ including the proportion of caucasians and hispanics $\left(\mathrm{X}^{2}(24, \mathrm{~N}=4,090)=4120.94, \mathrm{p}<.001\right)$. While statistical significance was found when comparing the non-aging and aging incarcerated population and their homelessness status, this was not true in the snapshot 1998, 2008, and 2018 December aging populations $\left(\mathrm{X}^{2}(23, \mathrm{~N}=4,090)=23.78, \mathrm{p}=.159, \mathrm{NS}\right)$. This was also true with custody level $\left(\mathrm{X}^{2}(6, \mathrm{~N}=4,090)=12.43, \mathrm{p}=.053, \mathrm{NS}\right)$ suggesting no change in proportion. However prior prison experience was significantly different $\left(\mathrm{X}^{2}(2, \mathrm{~N}=4,090)=54.36, \mathrm{p}<.001\right)$ suggesting a change in proportion; by 2018 , aging individuals were more likely to have prior prison experience than the 1998 or 2008 aging individuals. Additionally, the distribution of offense type varied across years $\left(\mathrm{X}^{2}(14, \mathrm{~N}=4,090)=76.71, \mathrm{p}<.001\right)$; particularly, while most aging incarcerated individuals were sentenced for a murder or sex offense, the distribution within the years was significantly different. In $1998,10.5 \%$ of this population was sentenced for a drug offense, while in 2018, this declined to 6.3\%. However, in 1998, 
$9.4 \%$ of this population was sentenced for an assault offense, while in 2018 , this increased to $13.8 \%$. Along with the differences found in offense type, significantly proportionally differences were found in sentence length $\left(\mathrm{X}^{2}(16, \mathrm{~N}=3,803)=226.94, \mathrm{p}=.022\right)$, time served $\left(\mathrm{X}^{2}(98, \mathrm{~N}=4,090)=274.29, \mathrm{p}<.001\right)$, or time to serve $\left(\mathrm{X}^{2}(40, \mathrm{~N}=2,215)=765.48, \mathrm{p}<.001\right)$.

Evaluating the incarcerated population by recidivism and violations from 1998 to 2018

Returns to prison and violations rates and frequencies were measured for individuals who were incarcerated on the 1998 and 2008 snapshot dates. Due to time constraints, recidivism and violations were evaluated for up to one year post release among the 2018 population. For the 1998 cohort, $21.9 \%$ of the younger cohort returned to prison within 36 months of release as compared to the $5 \%$ of the aging cohort. Within 60 months, another $7 \%$ of the younger cohort returned to prison while less than $2 \%$ of the aging individuals returned. The non-aging cohort who released accumulated 24,727 violations (majority consisted of a sex offense $(n=5,346,21.6 \%)$, reporting issue $(n=4,527,18.3 \%)$, or affirmative conduct ( $\mathrm{n}=3,688,14.9 \%)$ ) as compared to the 113 violations made by their older counterpart (majority consisted of either a drug or alcohol violation ( $\mathrm{n}=33,29.2 \%)$, a reporting issue ( $n=27,23.9 \%)$, or a sex offense $(n=23,20.4 \%)$ ). For the 2008 cohort, within 36 months of releasing, $22.8 \%$ of the younger cohort returned to prison as compared to the aging cohort (4.1\%). Within 60 months, another $6.9 \%$ of the younger cohort returned to prison while $1.2 \%$ of the aging cohort returned. The non-aging cohort who released accumulated 48,931 violations (majority consisted of a drug or alcohol ( $\mathrm{n}=22,096,45.2 \%$ ) or affirmative conduct $(\mathrm{n}=15,181,31.0 \%)$; the aging cohort who released accumulated 454 violations (majority consisted of a drug or alcohol violation ( $\mathrm{n}=174,28.3 \%)$, a sex offense $(n=103,22.7 \%)$, or affirmative conduct $(n=101,22.3 \%))$. For the 2018 cohort, within 12 months of releasing, $2.0 \%$ of the non-aging returned to prison as compared to the $0.5 \%$ of the aging cohort. The non-aging cohort who released accumulated 1,889 violations (majority consisted of a drug or alcohol violation $(\mathrm{n}=1,068,56.5 \%)$ or affirmative conduct $(\mathrm{n}=369,19.5 \%)$ ). The aging cohort who released accumulated 78 violations (majority consisted of a drug or alcohol violation $(n=49,62.8 \%)$ or affirmative conduct $(n=16$, $20.5 \%)$ ).

\section{Discussion}

This study reviewed snapshots of 1998, 2008, and 2018 incarcerated population data in efforts to evaluate the trends of the aging incarcerated population (ages 55 or older) over the past two decades. The findings highlight:

(a) The prevalence of the aging incarcerated population and the change in populations over the past two decades;

(b) The similarities and differences between the aging and non-aging incarcerated populations;

(c) The factors that distinguish the 1998, 2008, and 2018 aging incarcerated population; and

(d) The recidivism and violation rates of the 1998, 2008, and 2018 incarcerated population. This endeavor helped gain insight and knowledge into the impact of the aging incarcerated population.

\section{Limitations}

The complexity of the aging incarcerated is obscured by a few limitations. First, this study utilized December snapshot populations of the incarcerated individuals in 1998,2008 , and 2018. Some individuals from the 2018 snapshot population were the same individuals incarcerated from the 1998 or 2008 snapshot population, yielding a potential duplicative data sets. Furthermore, as this was snapshot populations, if an incarcerated individual was released prior to the December month, this incarcerated individual would not be presented in our data set-potentially not presenting the true impact of the aging incarcerated population. As two decades worth of data was attempted to be captured, a number of extraneous variables could have impacted the findings. These changes in law and policy could have impacted who and how the snapshot 1998, 2008, and 2018 population was sentenced and incarcerated, and the significant changes amongst the two decades of incarcerated data. Second, in comparing the aging to the non-aging incarcerated population, several measures were utilized. While findings revealed significant differences amongst the two age categories, it is important to note however, that some variance might come from specific variables. For example, sentence length, time served, and time to serve were dependent on the type of sentence; since the aging population were more likely to be sentenced to more serious crimes (e.g., murder or sex offense) than the non-aging population, there were potentially more likely to have longer sentence lengths, already served more time, and had more time to serve. Third, this endeavor employed a nonqualitative research design. While the data provided the ability to evaluate the impact of the graying population, a qualitative research design could provide greater detail that might offer more possibilities to garner insights that what can be found in the data sets. Additionally, qualitative research designs can provide the opportunity to understand through the lens of an individual's emotional and behavioral responses through questionnaires and surveys that might be lost in translating the data sets. Lastly, the recidivism rates of the 2018 incarcerated population were not obtained due to the need for release for at least 36 months, recidivism was measured for individuals who were incarcerated in 1998 and 2008

\section{Implications}

A growing rise in the number of aging incarcerated individuals is producing new hardships and challenges for the criminal justice and correctional system. As findings revealed, this aging incarcerated population is growing older at a quicker pace than non-aging incarcerated individuals. Correctional departments must be able to address this aging crisis. Endeavors such as this should continue to examine the factors that have accelerated the growth in the elderly inmate population, investigate innovative approaches for dealing with health and mental health issues of the aging inmates, and help increase Agency knowledge regarding the needs of the aging incarcerated population. Furthermore, finding possible avenues taken by other states in addressing the issues of an aging inmate population can help provide possible solutions to the overwhelming expenses of housing and caring for the elderly inmates. Through this work, a number of factors can be looked at. This includes consideration of policy changes, concern of geriatric and inmate physical and mental health, and consideration of new programs that target on the influences that impact the aging incarcerated population. The increase of the aging prison population is yielding many more challenges that correctional departments and facilities expected. Overall, correctional departments and facilities must house aging incarcerated individuals in facilities that were never constructed to shelter older individuals. Now, correctional departments and facilities must identify and find appropriate accommodations to best support their aging population. Some of the concerns include changing the structure of the facilities to allow for handi-capable systems, programs to support the cognitive and physical decline including providing assistance with daily activities, as well as hospice care and palliative services. Importantly, more research needs to be conducted to better address the necessary steps needed to support integral changes to support the aging incarcerated population. Along with the physical changes in the correctional facilities, there is a need for rehabilitation, educational, and recreational programs and services specifically targeted for the aging incarcerated individuals. Such programs and services can help facilitate the support and care of aging individuals, as it helps them engage in different activities designed for the elderly. Due to the unique physical, mental, and social health and care needs that come with an aging population, we need to reconsider the high price of incarcerating individuals who are aging, chronically or terminally ill. This includes but is not limited to special diets, physical assistance (e.g., walking cane, brace, or wheelchair), medical support (e.g., dentures, eyeglasses, prosthetic devices) and comorbid disabilities and diseases. Importantly, more research need be conducted to better address inmates' physical needs to provide adequate care.

Lastly, trainings to support the aging incarcerated individuals are important in order to address the care of the aging incarcerated individuals. This includes providing training and programs to educate correctional staff on the unique needs of the aging individuals. Most correctional staff have limited, if at all, any, training designed to support aging incarcerated individuals. Particularly, correctional staff need to be more vigilant of the challenges and risks that impact this unique group. For example, aging incarcerated individual are more likely to be victimized by their younger counterpart. Through specified training, correctional staff will be able to utilize additional measures and resources to protect this elderly group. This training would not only support the need to maintain safety around the correctional facilities, but also decrease potential legal issues for inadequately taking precautionary measures to effectively protect and support aging incarcerated individuals.

\section{References}

1. Cloyes KG, Burns KA (2015) Aging prisoners and the provision of correctional mental health. In: Trestman RL, Appelbaum KL, Metzner JL (Eds.), Oxford textbook of correctional psychiatry, USA, pp. 326-330.

2. Linder JF, Enders SR, Craig E, Richardson J, Meyers FJ (2002) Hospice care for the incarcerated in the United States: An introduction. Journal of Palliative Medicine 5(4): 549-552. 
3. Skarupski KA, Gross A, Schrack JA, Deal JA, Eber GB (2018) The health of America's aging prison population. Epidemiologic Reviews 40(1): 157-165.

4. Williams BA, Goodwin JS, Baillargeon J, Ahalt C, Walter LC (2012) Addressing the aging crisis in US criminal justice health care. Journal of the American Geriatrics Society 60(6): 1150-1156

5. Carson EA, Sabol WJ (2016) Aging of the state prison population, 1993-2013. US, pp. 1-38.

6. Nowotny KM, Cepeda A, James-Hawkins L, Boardman JD (2016) Growing old behind bars: Health profiles of the older male inmate population in the United States. Journal of Aging and Health 28(6): 935-956.
7. Ahalt C, Trestman RL, Rich JD, Greifinger RB, Williams BA (2013) Paying the price: The pressing need for quality, cost, and outcomes data to improve correctional health care for older prisoners. Journal of the American Geriatrics Society 61(11): 2013-2019.

8. Rakes S, Prost SG, Tripodi SJ (2018) Recidivism among older adults: Correlates of prison re-entry. Justice Policy Journal 15(1): 1-15.

9. United States Sentencing Commission (2005) Recidivism among federal offenders: A comprehensive overview.

10. Department of Justice, Office of Justice Programs, Bureau of Justice Statistics. 